\title{
CNS Demyelinating Attacks Requiring Ventilatory Support With Myelin Oligodendrocyte Glycoprotein or Aquaporin-4 Antibodies
}

\author{
Hannah H. Zhao-Fleming, MD, PhD, Cristina Valencia Sanchez, MD, PhD, Elia Sechi, MD, Jery Inbarasu, MD, \\ Eelco F. Wijdicks, MD, PhD, Sean J. Pittock, MD, John J. Chen, MD, PhD, Dean M. Wingerchuk, MD, \\ Brian G. Weinshenker, MD, Sebastian Lopez-Chiriboga, MD, Divyanshu Dubey, MBBS, \\ Jan-Mendelt Tillema, MD, Michel Toledano, MD, Hemang Yadav, MD, and Eoin P. Flanagan, MD
}

Neurology ${ }^{\circledR}$ 2021;97:e1351-e1358. doi:10.1212/WNL.0000000000012599

\begin{abstract}
Background and Objective

Severe attacks of myelin oligodendrocyte glycoprotein (MOG) antibody-associated disorder (MOGAD) and aquaporin-4 (AQP4) antibody-positive neuromyelitis optica spectrum disorder (AQP4-NMOSD) may require ventilatory support, but data on episodes are limited, particularly for MOGAD. We sought to compare the frequency, characteristics, and outcomes of MOGAD and AQP4-NMOSD attacks requiring ventilatory support.
\end{abstract}

\section{Methods}

This retrospective descriptive study identified Mayo Clinic patients (January 1, 1996-December 1, 2020) with MOGAD or AQP4-NMOSD and an attack requiring noninvasive or invasive ventilation at Mayo Clinic or an outside facility by searching for relevant terms in their electronic medical record. Inclusion criteria were (1) attack-related requirement for noninvasive (bilevel positive airway pressure or continuous positive airway pressure) or invasive respiratory support (mechanical ventilation); (2) MOG or AQP4 antibody positivity with fulfillment of MOGAD and AQP4NMOSD clinical diagnostic criteria, respectively; and (3) sufficient clinical details. We collected data on demographics, comorbid conditions, indication for and duration of respiratory support, MRI findings, treatments, and outcomes. The races of those with attacks requiring respiratory support were compared to those without such attacks in MOGAD and AQP4-NMOSD.

\section{Results}

Attacks requiring ventilatory support were similarly rare in patients with MOGAD ( 8 of $279,2.9 \%$ ) and AQP4-NMOSD (11 of 503 [2.2\%]) ( $p=0.63)$. The age at attack (median years [range]) (MOGAD 31.5 [5-47] vs AQP4-NMOSD 43 [14-65]; $p=0.01$ ) and percentage of female sex (MOGAD 3 of 8 [38\%] vs AQP4-NMOSD 10 of 11 [91\%]; $p=0.04$ ) differed. The reasons for ventilation differed between MOGAD (inability to protect airway from seizure, encephalitis or encephalomyelitis with attacks of acute disseminated encephalomyelitis 5 [62.5\%] or unilateral cortical encephalitis $3[37.5 \%]$ ) and AQP4-NMOSD (inability to protect airway from cervical myelitis $9[82 \%]$, rhombencephalitis $1[9 \%]$, or combinations of both $1[9 \%])$. Median ventilation duration for MOGAD was 2 days (range 1-7 days) vs 19 days (range 6-330 days) for AQP4-NMOSD ( $p=$ 0.01). All patients with MOGAD recovered, but 2 of 11 (18\%) patients with AQP4-NMOSD died of the attack. For AQP4-NMOSD, Black race was overrepresented for attacks requiring ventilatory support vs those without these episodes (5 of $11[45 \%]$ vs 88 of $457[19 \%] ; p=0.045$ ).

\author{
Correspondence \\ Dr. Flanagan \\ flanagan.eoin@mayo.edu
}

\section{MORE ONLINE}

CME Course

NPub.org/cmelist

From the Department of Neurology (H.H.Z.-F., C.V.S., E.S., J.I., E.F.W., S.J.P., J.J.C., B.G.W., D.D., J.-M.T., M.T., E.P.F.), Department of Laboratory Medicine and Pathology (S.J.P., D.D., E.P.F.), Department of Ophthalmology (.J.C.), and Division of Pulmonary and Critical Care Medicine (H.Y.), Mayo Clinic, Rochester, MN; Department of Neurology (D.M.W.), Mayo Clinic, Scottsdale, AZ; and Department of Neurology (S.L.-C.), Mayo Clinic, Jacksonville, FL.

Go to Neurology.org/N for full disclosures. Funding information and disclosures deemed relevant by the authors, if any, are provided at the end of the article.The Article Processing Charge was funded by the authors.

This is an open access article distributed under the terms of the Creative Commons Attribution-NonCommercial-NoDerivatives License 4.0 (CC BY-NC-ND), which permits downloading and sharing the work provided it is properly cited. The work cannot be changed in any way or used commercially without permission from the journal. 


\section{Glossary}

AQP4 = aquaporin-4; AQP4-IgG = AQP4 antibody; MOG = myelin oligodendrocyte glycoprotein; MOGAD = MOGantibody associated disorder; MOG-IgG = MOG antibody; MS = multiple sclerosis; NMO = neuromyelitis optica; NMOSD = NMO spectrum disorder.

\section{Discussion}

Ventilatory support is rarely required for MOGAD and AQP4-NMOSD attacks, and the indications differ. Compared to MOGAD, these attacks in AQP4-NMOSD may have higher morbidity and mortality, and those of Black race were more predisposed, which we suspect may relate to socially mediated health inequality.

Myelin oligodendrocyte glycoprotein (MOG) antibody (MOG-IgG)-associated disorder (MOGAD) and aquaporin-4 (AQP4) antibody (AQP4-IgG)-positive neuromyelitis optica (NMO) spectrum disorder (AQP4-NMOSD) are distinct CNS demyelinating diseases associated with attacks of transverse myelitis, brainstem syndromes, encephalitis, and acute disseminated encephalomyelitis. Rarely, such attacks can result in life-threatening neurogenic respiratory failure and inability to protect the airway (e.g., from severe upper cervical myelitis or encephalopathy), but data on such episodes are limited to a few subsets of case series ${ }^{1-3}$ or case reports. ${ }^{4}$ Those of Black race are more predisposed to develop AQP4-NMOSD. ${ }^{5,6}$ In addition, many prior studies have shown worse outcomes in this racial category that most likely relate to socially mediated health inequities, given their lower access to and quality of health care. ${ }^{7-9}$ In this study, we determined the frequency, at-risk racial categories, neurologic phenotype, and outcome of attacks that required ventilatory support in MOGAD and AQP4-NMOSD.

\section{Methods}

\section{Standard Protocol Approvals, Registrations, and Patient Consents}

The study was approved by the Mayo Clinic institutional review board. All patients or their parents consented to the use of their medical records for research purposes.

\section{Autoantibody Testing}

MOG-IgG and AQP4-IgG seropositivity for included patients was confirmed at the Mayo Clinic Neuroimmunology Laboratory (Rochester, MN) by live cell-based assay (MOG-IgG 8, AQP4IgG 8), inactivated cell-based assay (AQP4-IgG 1), ELISA (AQP4-IgG 1 ), or tissue-based immunofluorescence (AQP4 $\operatorname{IgG} 1$ ), as previously described. ${ }^{10,11}$ Both fresh and stored samples that were later retested were analyzed, and 5 of 8 (62.5\%) patients with MOGAD and 2 of $11(18 \%)$ with AQP4NMOSD had the episodes before their respective antibody biomarkers were commercially available.

\section{Identification of MOGAD and AQP4-NMOSD Attacks Needing Respiratory Support and Their Frequency}

In this retrospective observational study, patients with MOGAD and AQP4-NMOSD seen at Mayo Clinic from
January 1, 1996, to December 1, 2020, were identified through the Mayo Clinic neuroimmunology database. Their Mayo Clinic electronic medical records were then searched for terms relevant to attack-related requirement for respiratory support, and episodes occurring at Mayo Clinic or other medical facilities that were documented in our Mayo Clinic electronic medical record were included (Figure 1). The frequency of these episodes was defined as the number of patients with these attacks divided by the number of patients without these episodes in each group. Our inclusion criteria were (1) attackrelated requirement for noninvasive (bilevel positive airway pressure or continuous positive airway pressure) or invasive respiratory support (mechanical ventilation); (2) MOG-IgG or AQP4-IgG positivity with fulfillment of MOGAD and AQP4NMOSD clinical diagnostic criteria, respectively ${ }^{11-13}$; and (3) sufficient clinical details. We excluded those with other reasons for respiratory support (Figure 1).

\section{Data Collection}

We abstracted sex and race from the electronic medical record, which is self-reported by patients at their initial visit to Mayo Clinic. Data on broad racial categories that could be selected by patients included the following: American Indian or Alaskan Native, Asian, Black or African-American (referred to as Black for this study), Native Hawaiian or Pacific Islander, other, or White. A separate ethnicity question included the designation as Hispanic or Latino or not Hispanic or Latino. Data on sex were self-selected as a binary of male or female sex (1996-2017), although since 2017 a third transgender category has also been available to select. Data on age at onset and comorbid conditions (respiratory, cardiovascular, hematologic and obesity) of included patients with MOGAD and AQP4NMOSD with attacks requiring ventilatory support were $a b-$ stracted from the demographics section and physician notes within the electronic medical record. We also stratified the timeline of episodes between those encountered from January 1, 1996, to December 31, 2009, and those that occurred from January 1, 2010, to December 1, 2020. In addition, we collected data on the indication for and duration of respiratory support, MRI findings, treatments, and outcomes. The racial category of those with attacks requiring respiratory support was compared to that of individuals without such attacks in MOGAD and AQP4-NMOSD. In those with attacks requiring respiratory 
Figure 1 Flowchart for Identification of Attack-Related Need for Ventilatory Support in Patients With MOGAD and AQP4-NMOSD

A

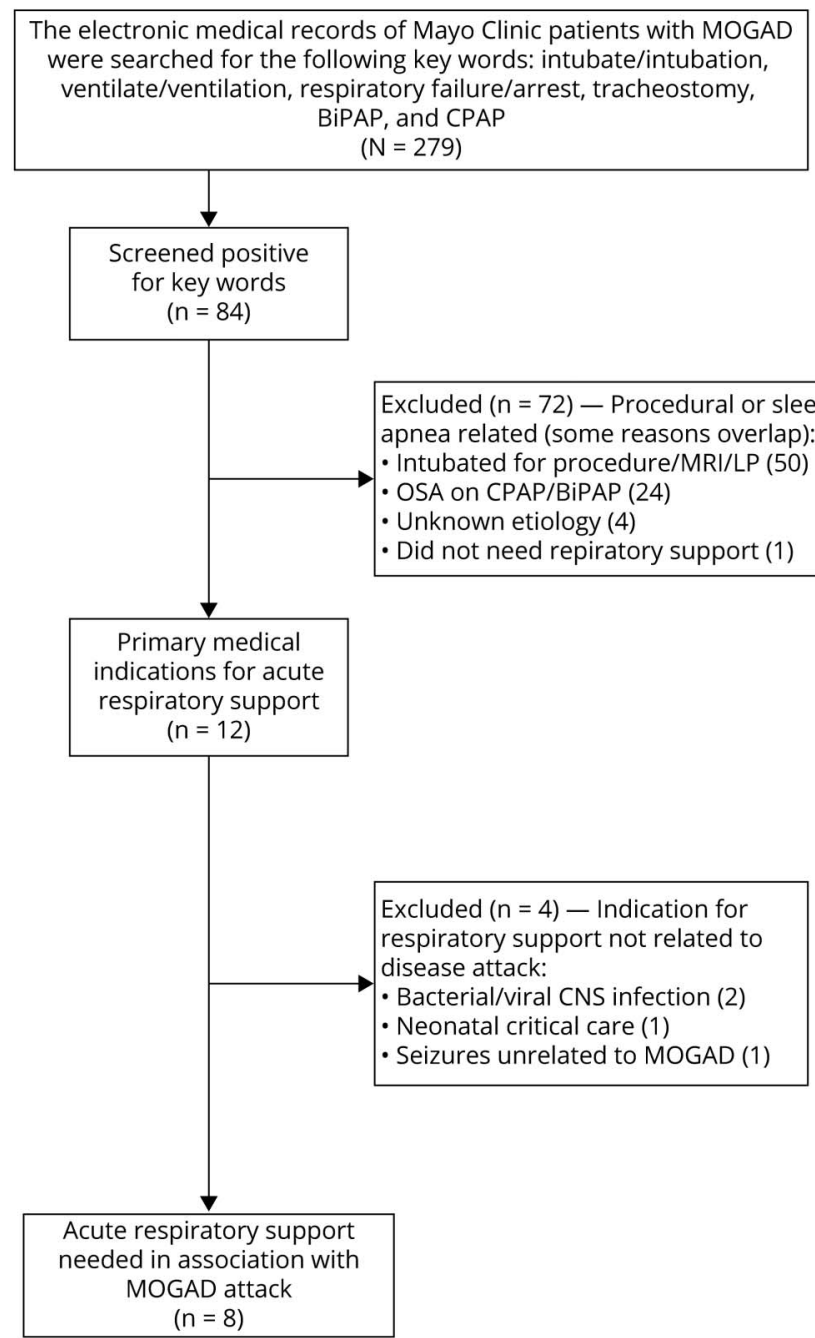

B

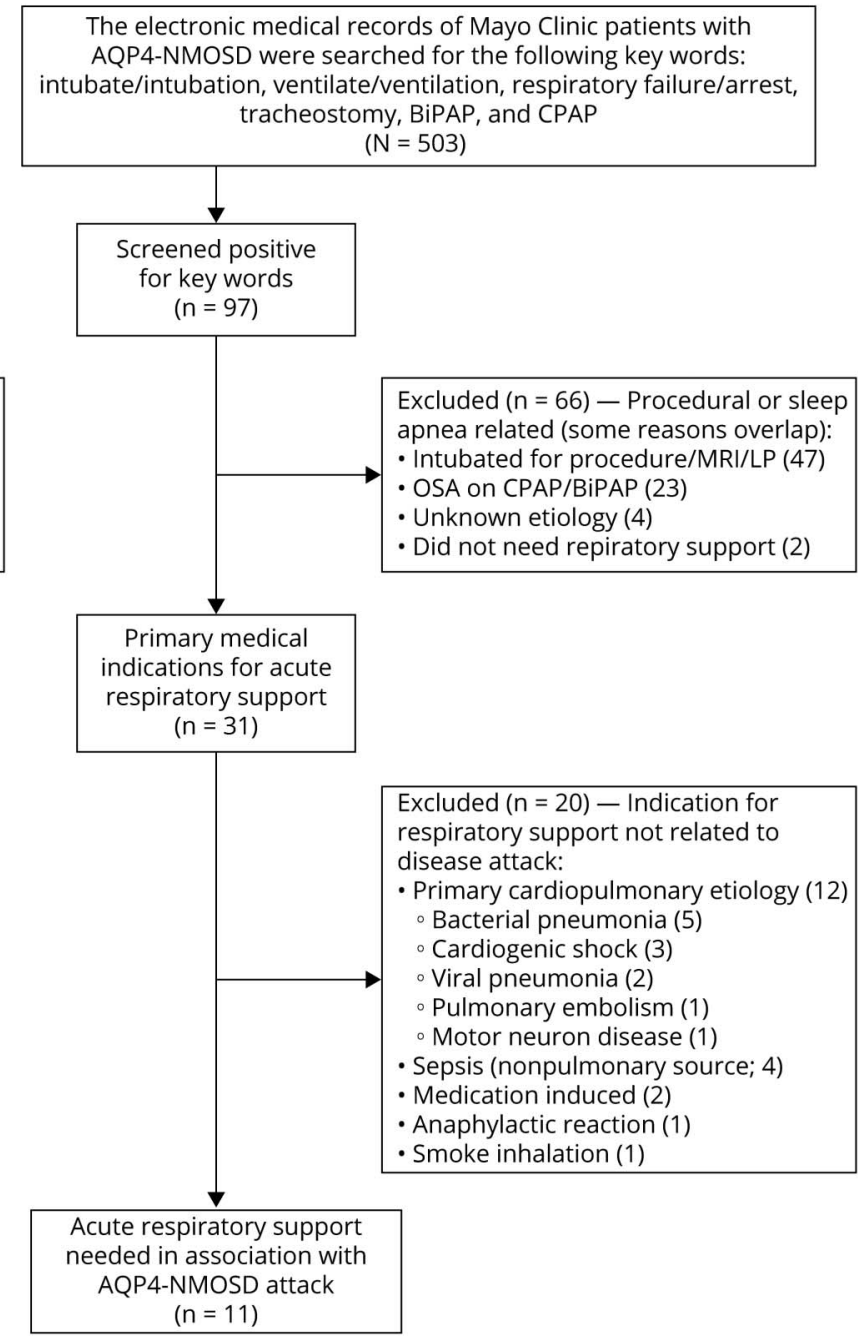

Flowchart shows the search strategy used to identify patients with myelin oligodendrocyte glycoprotein antibody-associated disorder (MOGAD) (A) and aquaporin-4 IgG seropositive-neuromyelitis optica spectrum disorder (AQP4-NMOSD) (B) included in this study. BiPAP = bilevel positive airway pressure; CPAP = continuous positive airway pressure; LP = lumbar puncture; OSA = obstructive sleep apnea.

support, we searched their medical records using the abbreviated term 'financ' to capture any financial hardship that could suggest socioeconomic contributors to a worse outcome and analyzed by race to explore whether any socioeconomic factors contributed to racial differences in outcome.

\section{Statistical Methodology}

Continuous and categorical variables were reported as median (range) and number (percent) and compared by use of the Wilcoxon rank-sum test and Fisher exact test, as appropriate (JMP Pro 14.1.0). Values of $p<0.05$ were considered statistically significant.

\section{Data Availability}

Anonymized data used for this study are available on reasonable request from the corresponding author.

\section{Results}

\section{Patient Cohort, Timeline, and Frequency of Attacks Requiring Ventilatory Support}

A total of 19 patients were included (MOGAD 8, AQP4NMOSD 11) who required ventilatory support from an attack at Mayo Clinic $(n=5)$ or an outside facility $(n=14)$. The majority of MOGAD episodes (7 of 8 [87.5\%]) occurred from 2010 to 2020, while a minority of AQP4-NMOSD episodes ( 4 of $11[36 \%]$ ) occurred over this time period ( $p=$ $0.06)$. Attack-related need for ventilatory support occurred in 8 of 279 (2.9\%) patients with MOGAD vs 11 of $503(2.1 \%)$ patients with AQP4-IgG-NMOSD $(p=0.63)$. In those with race data available, Black race was overrepresented in patients requiring respiratory support with AQP4-NMOSD vs those who did not (5 of 11 [45\%] vs 88 of 457 [19\%]; $p=0.045$ ). 
Table 1 Demographics, Comorbid Conditions, and Attack Details From MOGAD and AQP4-NMOSD Attacks Requiring Respiratory Support

\begin{tabular}{|c|c|c|c|}
\hline & $\operatorname{MOGAD}(n=8)^{a}$ & $\begin{array}{l}\text { AQP4-NMOSD } \\
(\mathrm{n}=11)^{\mathrm{a}}\end{array}$ & $p$ Value \\
\hline \multicolumn{4}{|l|}{ Demographics } \\
\hline $\begin{array}{l}\text { Age at attack with RF, median } \\
\text { (range), y }\end{array}$ & $31.5(5-47)$ & $43(14-65)$ & 0.01 \\
\hline $\begin{array}{l}\text { Pediatric (age }<18 \text { y at time of attack), } \\
\text { n (\%) }\end{array}$ & $3 / 8(38)$ & 1/11 (9) & 0.26 \\
\hline Female sex, n (\%) & $3 / 8(38 \%)$ & 10/11 (91\%) & 0.04 \\
\hline \multicolumn{4}{|l|}{ Racial category, n (\%) } \\
\hline White $^{\mathrm{b}}$ & $7 / 8(88)$ & $4 / 11(36)$ & 0.06 \\
\hline Black $^{\text {b }}$ & $0 / 8(0)$ & $5 / 11(45)$ & 0.04 \\
\hline \multicolumn{4}{|l|}{$\begin{array}{l}\text { Comorbid conditions, } \\
\text { n (\%) }\end{array}$} \\
\hline Respiratory disease & $1 / 8(13)^{c}$ & $2 / 11(18)^{d}$ & 1 \\
\hline Smoker & $0 / 8(0)$ & $1 / 9(11)$ & 1 \\
\hline Myasthenia gravis & $0 / 8(0)$ & 0/11 (0) & NA \\
\hline Other & $2 / 8(25)^{\mathrm{e}}$ & $6 / 11(55)^{f}$ & 0.35 \\
\hline \multicolumn{4}{|l|}{$\begin{array}{l}\text { Attack and ventilatory } \\
\text { details }\end{array}$} \\
\hline $\begin{array}{l}\text { Episode represented first attack, } \\
\text { n (\%) }\end{array}$ & $7 / 8(88)$ & 2/11 (18) & 0.006 \\
\hline $\begin{array}{l}\text { Median EDSS score just before } \\
\text { attack }\end{array}$ & $0(0-3.5)$ & $4(0-8)$ & 0.02 \\
\hline $\begin{array}{l}\text { Encephalitis/rhombencephalitis, } \\
\text { n (\%) }\end{array}$ & $8 / 8(100)$ & 2/11 (18) & $<0.001$ \\
\hline Quadriparesis, n (\%) & $2 / 8(25)$ & $11 / 11(100)$ & 0.001 \\
\hline $\begin{array}{l}\text { Median time (range) from disease } \\
\text { onset to episode, } y\end{array}$ & $0(0-22)$ & $3(0-21)$ & 0.02 \\
\hline $\begin{array}{l}\text { Median (range) duration of } \\
\text { respiratory support, } d\end{array}$ & $2(1-7)$ & $19(6-330)$ & 0.01 \\
\hline $\begin{array}{l}\text { Mechanical ventilation, } \\
\mathrm{n}(\%)\end{array}$ & $8 / 8(100)^{g}$ & $9 / 11(82)^{\mathrm{h}}$ & 0.49 \\
\hline $\begin{array}{l}\text { Noninvasive ventilation (BiPAP/CPAP), } \\
\mathrm{n}(\%)\end{array}$ & $0 / 8(0)$ & $2 / 11(18)^{i}$ & 0.49 \\
\hline $\begin{array}{l}\text { Tracheostomy required, } \\
\text { n (\%) }\end{array}$ & $1 / 8(13)^{j}$ & $5 / 11(45)^{k}$ & 0.18 \\
\hline $\begin{array}{l}\text { Aspiration contributing to need for intubation, } \\
\mathrm{n}(\%)\end{array}$ & $1 / 5(20)$ & $1 / 3(33)$ & 1.0 \\
\hline $\begin{array}{l}\text { Abnormal pulmonary imaging (CXR or CT of the chest), } \\
n(\%)\end{array}$ & $1 / 5(20)^{\prime}$ & $2 / 3(67)^{m}$ & 0.46 \\
\hline ABG abnormal, $\mathrm{n}(\%)$ & $1 / 3(33)^{n}$ & $1 / 1(100)^{\circ}$ & 1.0 \\
\hline Elevated hemi-diaphragm, n (\%) & $0 / 5(0)$ & $2 / 3(67)$ & 0.11 \\
\hline Developed ventilator-associated pneumonia, n (\%) & $1 / 5(20)$ & $1 / 3(33)$ & 1.0 \\
\hline \multicolumn{4}{|l|}{ CSF analysis at the time of an attack, $n(\%)$} \\
\hline Elevated white blood cell count (normal range, $0-5 / \mu \mathrm{L}$ ) & $4 / 4(100)^{\mathrm{p}}$ & $3 / 3(100)^{q}$ & NA \\
\hline
\end{tabular}


Table 1 Demographics, Comorbid Conditions, and Attack Details From MOGAD and AQP4-NMOSD Attacks Requiring Respiratory Support (continued)

\begin{tabular}{llll}
\hline & MOGAD $(n=8)^{\mathrm{a}}$ & $\begin{array}{l}\text { AQP4-NMOSD } \\
(\mathrm{n}=11)^{\mathrm{a}}\end{array}$ & $p$ Value \\
\hline Positive oligoclonal bands $(\geq 2$ unique CSF bands) & $0 / 3(0)$ & $0 / 2(0)$ & NA
\end{tabular}

Abbreviations: $\mathrm{ABG}=$ arterial blood gas; $\mathrm{AQP4-NMOSD}=$ aquaporin-4 IgG seropositive-neuromyelitis optica spectrum disorder; BiPAP = bilevel positive airway pressure; CPAP = continuous positive airway pressure; CXR = chest $\mathrm{X}$-ray; EDSS = Expanded Disability Status Scale; IVIG = IV immunoglobulin; MOGAD = Myelin Oligodendrocyte Glycoprotein antibody-associated disorder; NA = not applicable; PLEX = plasma exchange; RF = respiratory failure.

a In those with details available.

${ }^{b}$ The other racial category for each disease is included here: MOGAD (Asian 1) and AQP4-NMOSD (Asian 1, other 1). Two patients selected Hispanic ethnicity (1 with MOGAD included as White racial category and 1 with AQP4-NMOSD who selected other racial category).

'Obstructive sleep apnea $\mathrm{n}=1$.

dObstructive sleep apnea $\mathrm{n}=2$.

e Hypertension $\mathrm{n}=2$.

${ }^{f}$ One or more of the following: obesity $n=4$, hypertension $n=2$, pernicious anemia $n=1$, mitral valve prolapse $n=1$.

${ }^{g}$ Ventilation setting details available in 4 patients: pressure support ventilation $n=3$, adaptive pressure ventilation mode $n=1$. Sedation details available in 4 and included 1 or more of the following: propofol $n=4$, dexmedetomidine $n=2$, benzodiazepines $n=2$.

${ }^{\mathrm{h}}$ Ventilation setting details available in 2: pressure-regulated volume control in 1 and synchronized intermittent mandatory ventilation in 1. Sedation details available in 2 and included 1 or more of the following: propofol $n=1$, dexmedetomidine $n=1$, benzodiazepines $n=1$.

'BiPAP $n=1$, CPAP $n=1$.

i Details available in 1 regarding the reason for tracheostomy and was from difficulty with clearing secretions.

${ }^{k}$ Details available in 1 regarding the reason for tracheostomy and was from recurrent left lung collapse from mucus plugs and diaphragm weakness on that side.

'The single abnormality was bilateral ground glass opacities on chest CT suggestive of aspiration.

$\mathrm{m}$ The abnormalities included left lung complete opacification on CXR in the setting of left lung collapse from a mucus plug with an elevated hemidiaphragm in that setting in 1 patient and an elevated right hemidiaphragm in the other patient

${ }^{n}$ Details of the abnormal arterial blood gas: $\mathrm{pH} 7.19, \mathrm{PcO}_{2} 79 \mathrm{~mm} \mathrm{Hg}, \mathrm{PO}_{2} 80 \mathrm{~mm} \mathrm{Hg}$

- Details of the abnormal arterial blood gas: $\mathrm{pH} 7.34, \mathrm{PCO}_{2} 55 \mathrm{~mm} \mathrm{Hg}, \mathrm{Po}_{2} 80 \mathrm{~mm} \mathrm{Hg}$.

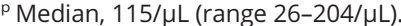

${ }^{9}$ Median 34/ $\mu \mathrm{L}$ (range, $\left.10-240 / \mu \mathrm{L}\right)$.

The risk of attack-related ventilatory support was not associated with other racial categories in the AQP4-NMOSD group or any racial category in the MOGAD group. Among the patients with MOGAD requiring ventilatory support, 1 of 4 with financial status documented reported financial hardship and was of White race and Hispanic ethnicity. Among the patients with AQP4-NMOSD requiring ventilatory support, 3 of 5 with financial status documented reported financial hardship, including 2 of Black race and 1 of Asian race.

\section{Clinical and Radiologic Characteristics of Attacks Requiring Respiratory Support}

The demographics, clinical features, comorbid conditions, diagnostic tests, treatments, and outcome of patients with

Table 2 Treatments and Outcome From MOGAD and AQP4-NMOSD Attacks Requiring Respiratory Support

\begin{tabular}{|c|c|c|c|}
\hline & $\operatorname{MOGAD}(n=8)^{a}$ & AQP4-NMOSD $(n=11)^{a}$ & $p$ Value \\
\hline \multicolumn{4}{|l|}{ Attack immunotherapy, $\mathrm{n}(\%)$} \\
\hline IV corticosteroids & $7 / 8(88)$ & $9 / 10(90)$ & 1 \\
\hline PLEX & $2 / 8(25)$ & $9 / 10(90)$ & 0.01 \\
\hline IVIG & $0 / 8(0)$ & $1 / 10(10)$ & 1.0 \\
\hline \multicolumn{4}{|l|}{ Outcome } \\
\hline Death, n (\%) & $0 / 8(0)$ & 2/11 (18) & 0.49 \\
\hline Chronic tracheostomy (>6 mo) in those who survived, $n(\%)$ & $0 / 8(0)$ & $1 / 9(11)$ & 1 \\
\hline Median (range) EDSS score in follow-up after attack & $1.25(0-6.5)$ & $6.5(3-10)$ & 0.002 \\
\hline Recurrent attacks after ventilatory support episode in those surviving episode, $n$ (\%) & $6 / 8(75)^{b}$ & $7 / 9(78)^{c}$ & 1.0 \\
\hline $\begin{array}{l}\text { Median (range) time from ventilatory support episode to last clinical follow-up in } \\
\text { those surviving episode, mo }\end{array}$ & $53(3-121)$ & $42.5(5-323)$ & 0.5 \\
\hline $\begin{array}{l}\text { Abbreviations: AQP4-NMOSD = aquaporin-4-IgG seropositive neuromyelitis optica spectrun } \\
\text { immunoglobulin; MOGAD = myelin oligodendrocyte glycoprotein antibody-associated disord } \\
\text { a In those with details available. } \\
\text { b Optic neuritis } n=4 \text {, transverse myelitis } n=1 \text {, encephalitis with seizures } n=1 \text {. } \\
\text { c Optic neuritis } n=2 \text {, transverse myelitis } n=4 \text {, unknown } n=1 \text {. }\end{array}$ & $\begin{array}{l}\text { lisorder; } \text { EDSS = Ex } \\
; P L E X=\text { plasma exc }\end{array}$ & $\begin{array}{l}\text { anded Disability Status Scal } \\
\text { ange. }\end{array}$ & $I V I G=I V$ \\
\hline
\end{tabular}


Figure 2 Representative MRIs of the Brain and Spinal Cord of Patients During the Acute MOGAD or AQP4-NMOSD Attack That Required Ventilatory Support
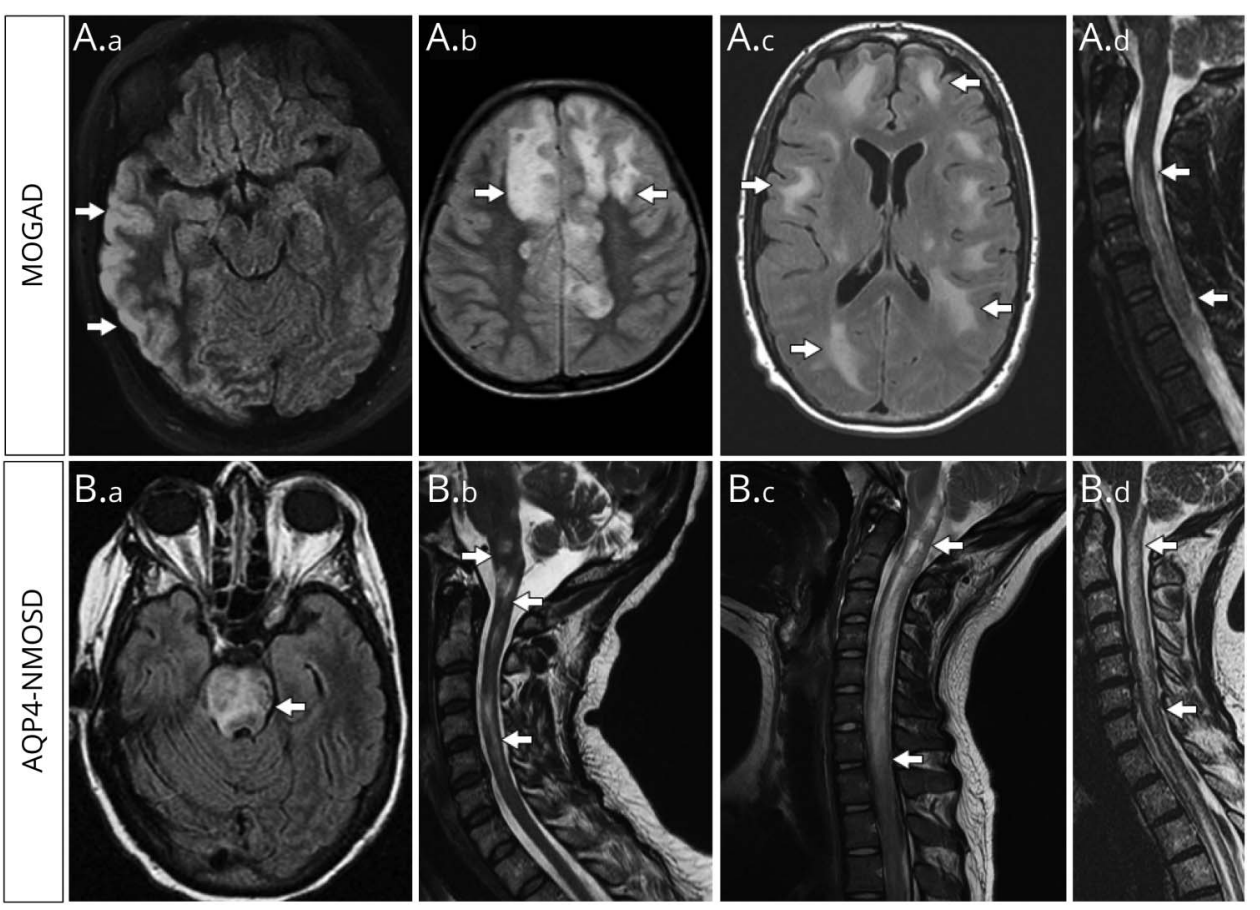

Images of myelin oligodendrocyte glycoprotein antibody-associated disorder (MOGAD) (A) and aquaporin4 IgG-neuromyelitis optica spectrum disorder (AQP4-NMOSD) (B) are shown. Brain axial fluid-attenuated inversion recovery (FLAIR) image reveals unilateral cortical T2 hyperintensity and swelling in the right temporal lobe (A.a, arrows) in MOGAD. Brain axial FLAIR image reveals bifrontal $T 2$ hyperintensities (A.b, arrows) in MOGAD. Axial FLAIR reveals multifocal bilateral white matter T2 hyperintensities (A.C, arrows) in MOGAD. Cervical spine sagittal T2 images reveal a cervical
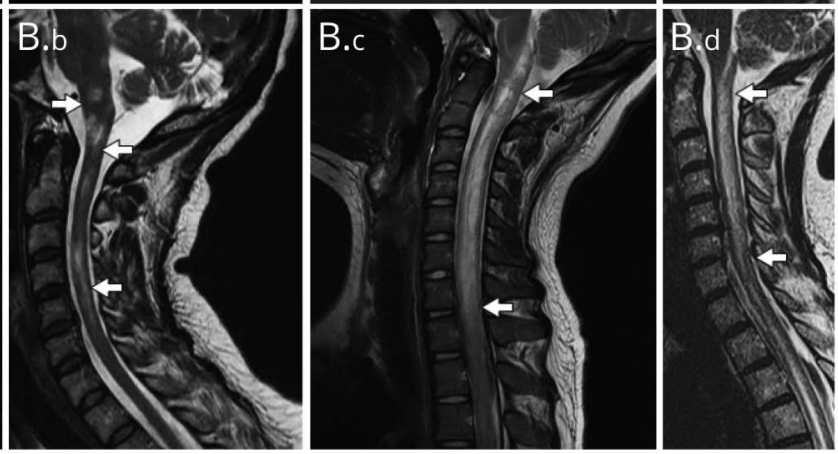
longitudinally extensive myelitis lesion (A.d, arrows) in MOGAD. Brain axial FLAIR images reveal diffuse pontine T2 hyperintensity (B.a, arrow) in AQP4-NMOSD. Cervical spine sag ittal T2-weighted images reveals medulla T2-hyperintensity (B.b, upper arrow) coexisting with T2-hyperintense myelitis discontinuous lesion (B.b, lower 2 arrows) in the same patient (with only delayed imaging 1 month after the attack available) and 2 additional patients with longitudinally extensive T2 hyperintensities (B.c and B.d, arrows) with AQP4 NMOSD.

MOGAD and AQP4-NMOSD requiring respiratory support are summarized in Tables 1 and 2 .

\section{Patients With MOGAD}

The attack requiring ventilatory support was the first attack in 7 (87.5\%) and occurred as a subsequent relapse in 1 (12.5\%) receiving fingolimod at that time for presumed multiple sclerosis (MS). The attack types and contributory clinical features leading to the need for airway protection included acute disseminated encephalomyelitis in 5 (status epilepticus 2, severe encephalomyelitis with quadriparesis 2, severe encephalitis 1) and unilateral cortical encephalitis in 3 (seizures/status epilepticus 3 [ 1 with temporary increased intracranial pressure of $600 \mathrm{~mm} \mathrm{H}_{2} \mathrm{O}$ requiring mannitol]). Concomitant acute bilateral optic neuritis occurred in 2 . Antiseizure medications used included levetiracetam in 4, carbamazepine in 1 , and valproic acid in 1 . During attacks, MRI abnormalities included 1 or more of supratentorial T2 lesions (Figure 2, A.b and A.c) in 5, infratentorial T2 lesions in 4, spinal T2 lesions (all longitudinally extensive) in 3 (Figure 2, A.d), unilateral cortical swelling with T2 hyperintensity (Figure 2, A.a) and leptomeningeal enhancement in 3 , and optic nerve enhancement in 2 .

\section{Patients With AQP4-NMOSD}

The attack requiring ventilatory support was the first attack in 2 (18\%) and occurred as a subsequent relapse in 9 (82\%). In 7 of 9 , details of maintenance treatments (if any) at the time of the attack were available: AQP4-NMOSD-targeted medications in 1 (mycophenolate mofetil and prednisone), MS-targeted medications in 3 (natalizumab and interferon beta 1, natalizumab 1, interferon beta 1), and no immunosuppressant medications in 3 . The indications for ventilatory support included neurogenic respiratory failure or inability to protect airway from cervical myelitis and quadriparesis in 9 (82\%), rhombencephalitis in 1 (9\%), and a combination of both in 1 (9\%). Concomitant attacks in other locations included area postrema syndrome $(n=2)$ and bilateral optic neuritis $(\mathrm{n}=1)$. Notable acute MRI lesions included a longitudinally extensive spinal T2 lesion (Figure 2, B.c and B.d) in 7 of 7 available (median vertebral length 8, range 4-19; 6 of 7 [86\%] extended to medulla [Figure 2, B.b, B.c, and B.d]) and infratentorial diffuse T2 lesion in 3 of 7 (43\%: Figure 2, B.a).

\section{Discussion}

We found that MOGAD and AQP4-NMOSD attacks needing ventilatory support were rare. The indication for ventilatory support with MOGAD was typically seizures or encephalitis, while with AQP4-NMOSD it was mostly from severe quadriparesis with cervical myelitis, and invasive rather than noninvasive ventilation predominated in both groups. In AQP4NMOSD, these episodes had higher morbidity and mortality, and those of Black race were more predisposed.

The frequency of respiratory failure in AQP4-NMOSD of 2.2\% with a mortality of $18 \%$ that we report was less than in a 1999 NMO study in which 33\% of patients with relapsing and $9 \%$ of patients with monophasic disease had respiratory failure with a mortality of $84 \%$. $^{3}$ The lower frequency we found may reflect the discovery of AQP4-IgG in 2004, allowing diagnosis of milder, 
more limited forms of NMOSD and earlier use of more targeted attack-prevention immunosuppressants that may prevent these severe attacks. ${ }^{14}$ Frequent plasmapheresis use may account for our lower mortality, and early use with severe myelitis may prevent respiratory failure. ${ }^{15}$ It is notable that just 1 patient was receiving AQP4-NMOSD attack prevention treatment at the time of their attack, while 3 were taking MS treatments (natalizumab, interferon beta) known to worsen AQP4-NMOSD. ${ }^{16,17}$ The lack of availability of AQP4-IgG before 2004 and lower sensitivity of early-generation assays prevented many of these patients from being correctly diagnosed and treated and likely contributed to these events occurring. Disability before and after these severe attacks was greater in AQP4-NMOSD and may also increase respiratory failure from nonattack etiologies (e.g., aspiration pneumonia), but that was not the focus of this study.

Patients with AQP4-NMOSD of Black race were predisposed to attack-related respiratory failure in our AQP4NMOSD cohort, and this finding warrants emphasis. The frequency of attack-related requirement for ventilatory support may be higher in other AQP4NMOSD cohorts with higher proportions of Black race. The increased risk of respiratory failure among Black patients in this study is consistent with many prior reports in AQP4-NMOSD that show that this racial group has a worse prognosis. ${ }^{7-9}$ For example, a prior study reported that those of African ancestry accounted for $41 \%$ of NMOSD cases but $90 \%$ of the mortality. ${ }^{9}$ We suspect that the worse outcome is most likely related to socioeconomic factors, including inequity in access to and quality of health care, which is partly supported by Black race predominating among those with respiratory failure who reported financial hardship. However, the small numbers limited full analysis of socioeconomic factors in this report, which is a major limitation of our study. ${ }^{18}$ A particular focus on ways to improve outcomes among Black patients with AQP4NMOSD is needed given their predilection to both develop this disease and have a worse prognosis., ${ }^{5,6}$

In MOGAD, these episodes were usually the first attack, which makes prevention difficult, but most did go on to have further relapses, suggesting that maintenance attack prevention immunosuppression in this subset of patients after a single severe life-threatening attack could be considered. Airway protection for seizures or severe encephalopathy predominated, including from the novel unilateral cortical encephalitis phenotype (Figure 2, A.a), highlighting that it is not always benign. ${ }^{19}$ These attacks occurred in $2.8 \%$ of patients with MOGAD with $0 \%$ mortality, while a prior study reported 3 of $48(6.3 \%)$ with neurogenic respiratory failure (rhombencephalitis 2 , myelitis 1 ) and 33\% mortality, although encephalopathy or seizure indications were not reported. ${ }^{1}$ The better outcome in MOGAD vs AQP4-NMOSD may reflect the good recovery reported from most MOGAD attacks, ${ }^{20-22}$ better supportive treatment, and more MOGAD episodes occurring recently and most occurring as the first attack without preexisting disability. The lower proportion of MOGAD requiring plasma exchange may be from the more rapid recovery with shorter duration of intubation, better response to corticosteroids in MOGAD, and plasma exchange being better studied in AQP4-NMOSD. ${ }^{15,23}$
Study limitations include the retrospective design and potential for referral bias. In addition, in some patients, these diagnoses were assigned retrospectively on the basis of retesting of archived samples because these antibody biomarkers were not available for the entire study timeline (1996-2020), and it should be noted that AQP4-IgG was identified before MOG-IgG. This could have influenced both the total number of cases identified and their outcome. In the future, with earlier diagnosis and better disease-specific treatments, we expect that episodes may become less frequent and less severe. Attacks requiring ventilatory support occurring at outside facilities could have been underestimated if they were not documented in our electronic medical records. However, we did capture many episodes that occurred at other facilities, and such life-threatening attacks would be expected to be documented during a comprehensive neurology assessment at our facility. Finally, data on pulmonary aspects (e.g., chest imaging) were available in very few, limiting analysis of these aspects.

This study provides insight into a rare, life-threatening, attackrelated complication of MOGAD and AQP4-NMOSD of which clinicians should be aware.

\section{Study Funding}

This study was funded by an RO1 from the National Institute of Neurologic Disorders and Stroke (R01NS113828). The authors also acknowledge the Guthy Jackson Foundation for its support.

\section{Disclosure}

H.H. Zhao-Fleming, C. Valencia Sanchez, E. Sechi, and J. Inbarasu report no disclosures. E.F. Wijdicks reports no disclosures other than royalties for books with Oxford University Press. S.J. Pittock reports grants, personal fees, and nonfinancial support from Alexion Pharmaceuticals, Inc; grants, personal fees, nonfinancial support, and other support from MedImmune, Inc/Viela Bio; and personal fees for consulting from Genentech/Roche. He has a patent, patent No. 8,889,102 (application No. 12-678350, Neuromyelitis Optica Autoantibodies as a Marker for Neoplasia), issued and a patent, patent No. 9,891,219B2 (application 12-573942, Methods for Treating Neuromyelitis Optica [NMO] by Administration of Eculizumab to an Individual That is Aquaporin-4 (AQP4)-IgG Autoantibody Positive), issued. J.J. Chen reports no disclosures. D.M. Wingerchuk reports receiving consulting fees from Genentech, Roche, Biogen, Novartis, TG Therapeutics, Third Rock Ventures, Reistone, and Mitsubuishi Tanabe; serving as member of a clinical trial adjudication committee for VielaBio; and receiving research funds paid to Mayo Clinic from Alexion and TerumoBCT. B.G. Weinshenker receives royalties from RSR Ltd, Oxford University, Hospices Civil de Lyon, and MVZ Labor PD Dr. Volkmann und Kollegen GbR for a patent of NMO-IgG as a diagnostic test for NMO and related disorders. He serves as a member of an adjudication committee for clinical trials in NMO 
conducted by VielaBio and Alexion. He is a consultant for Chugai, Roche, Genentech, and Mitsubishi Tanabe regarding clinical trials for NMO. S. Lopez-Chiriboga, D. Dubey, J.-M. Tillema, M. Toledano, and H. Yadav report no disclosures. E.P. Flanagan has served on advisory boards for Alexion, Genentech, and Horizon Therapeutics. He has received speaker honoraria from Pharmacy Times, royalties from UpToDate. He was a site primary investigator in a randomized clinical trial on Inebilizumab in neuromyelitis optica spectrum disorder run by Medimmune/Viela-Bio/ Horizon Therapeutics. He has received funding from the NIH (R01NS113828), is a member of the medical advisory board of the MOG project and an editorial board member of the Journal of the Neurological Sciences and Neuroimmunology Reports. Go to Neurology.org/N for full disclosures.

\section{Publication History}

Received by Neurology February 4, 2021. Accepted in final form July 1, 2021.

Appendix Authors

\begin{tabular}{|c|c|c|}
\hline Name & Location & Contribution \\
\hline $\begin{array}{l}\text { Hannah H. Zhao- } \\
\text { Fleming, MD, PhD }\end{array}$ & $\begin{array}{l}\text { Mayo Clinic, } \\
\text { Rochester, } \\
\text { MN }\end{array}$ & $\begin{array}{l}\text { Designed and conceptualized } \\
\text { study; drafted the manuscript and } \\
\text { figures; analyzed and interpreted } \\
\text { the data. }\end{array}$ \\
\hline $\begin{array}{l}\text { Cristina Valencia } \\
\text { Sanchez, MD, PhD }\end{array}$ & $\begin{array}{l}\text { Mayo Clinic, } \\
\text { Rochester, } \\
\text { MN }\end{array}$ & $\begin{array}{l}\text { Analyzed and interpreted the data; } \\
\text { revised the manuscript for intellectual } \\
\text { content. }\end{array}$ \\
\hline Elia Sechi, MD & $\begin{array}{l}\text { Mayo Clinic, } \\
\text { Rochester, } \\
\text { MN }\end{array}$ & $\begin{array}{l}\text { Statistical analysis; interpreted the } \\
\text { data; revised the manuscript for } \\
\text { intellectual content. }\end{array}$ \\
\hline Jery Inbarasu, MD & $\begin{array}{l}\text { Mayo Clinic, } \\
\text { Rochester, } \\
\text { MN }\end{array}$ & $\begin{array}{l}\text { Designed and conceptualized study; } \\
\text { drafted the manuscript; analyzed and } \\
\text { interpreted the data. }\end{array}$ \\
\hline $\begin{array}{l}\text { Eelco F. Wijdicks, } \\
\text { MD, PhD }\end{array}$ & $\begin{array}{l}\text { Mayo Clinic, } \\
\text { Rochester, } \\
\text { MN }\end{array}$ & $\begin{array}{l}\text { Interpreted the data; revised the } \\
\text { manuscript for intellectual content. }\end{array}$ \\
\hline $\begin{array}{l}\text { Sean J. Pittock, } \\
\text { MD }\end{array}$ & $\begin{array}{l}\text { Mayo Clinic, } \\
\text { Rochester, } \\
\text { MN }\end{array}$ & $\begin{array}{l}\text { Interpreted the data; revised the } \\
\text { manuscript for intellectual content. }\end{array}$ \\
\hline $\begin{array}{l}\text { John J. Chen, MD, } \\
\text { PhD }\end{array}$ & $\begin{array}{l}\text { Mayo Clinic, } \\
\text { Rochester, } \\
\text { MN }\end{array}$ & $\begin{array}{l}\text { Interpreted the data; revised the } \\
\text { manuscript for intellectual content. }\end{array}$ \\
\hline $\begin{array}{l}\text { Dean M. } \\
\text { Wingerchuk, MD }\end{array}$ & $\begin{array}{l}\text { Mayo Clinic, } \\
\text { Scottsdale, AZ }\end{array}$ & $\begin{array}{l}\text { Interpreted the data; revised } \\
\text { the manuscript for intellectual } \\
\text { content. }\end{array}$ \\
\hline $\begin{array}{l}\text { Brian G. } \\
\text { Weinshenker, MD }\end{array}$ & $\begin{array}{l}\text { Mayo Clinic, } \\
\text { Rochester, } \\
\text { MN }\end{array}$ & $\begin{array}{l}\text { Interpreted the data; revised the } \\
\text { manuscript for intellectual content. }\end{array}$ \\
\hline $\begin{array}{l}\text { Sebastian Lopez- } \\
\text { Chiriboga, MD }\end{array}$ & $\begin{array}{l}\text { Mayo Clinic, } \\
\text { Jacksonville, } \\
\text { FL }\end{array}$ & $\begin{array}{l}\text { Interpreted the data; revised the } \\
\text { manuscript for intellectual content. }\end{array}$ \\
\hline $\begin{array}{l}\text { Divyanshu } \\
\text { Dubey, MBBS }\end{array}$ & $\begin{array}{l}\text { Mayo Clinic, } \\
\text { Rochester, } \\
\text { MN }\end{array}$ & $\begin{array}{l}\text { Interpreted the data; revised the } \\
\text { manuscript for intellectual content. }\end{array}$ \\
\hline
\end{tabular}

\section{Appendix (continued)}

\begin{tabular}{lll}
\hline Name & Location & Contribution \\
\hline $\begin{array}{l}\text { Jan-Mendelt } \\
\text { Tillema, MD }\end{array}$ & $\begin{array}{l}\text { Mayo Clinic, } \\
\text { Rochester, } \\
\text { MN }\end{array}$ & $\begin{array}{l}\text { Interpreted the data; revised the } \\
\text { manuscript for intellectual content. }\end{array}$ \\
\hline $\begin{array}{l}\text { Michel Toledano, } \\
\text { MD }\end{array}$ & $\begin{array}{l}\text { Mayo Clinic, } \\
\text { Rochester, } \\
\text { MN }\end{array}$ & $\begin{array}{l}\text { Interpreted the data; revised the } \\
\text { manuscript for intellectual content. }\end{array}$ \\
$\begin{array}{l}\text { Hemang Yadav, } \\
\text { MD }\end{array}$ & $\begin{array}{l}\text { Mayo Clinic, } \\
\text { Rochester, }\end{array}$ & $\begin{array}{l}\text { Interpreted the data; revised the } \\
\text { manuscript for intellectual content. }\end{array}$ \\
\hline $\begin{array}{l}\text { Eoin P. Flanagan, } \\
\text { MD }\end{array}$ & $\begin{array}{l}\text { Mayo Clinic, } \\
\text { Rochester, } \\
\text { MN }\end{array}$ & $\begin{array}{l}\text { Designed and conceptualized study; } \\
\text { analyzed and interpreted the data; } \\
\text { revised the manuscript for intellectual } \\
\text { content; study supervision. }\end{array}$ \\
\hline
\end{tabular}

\section{References}

1. Jarius S, Ruprecht K, Kleiter I, et al. MOG-IgG in NMO and related disorders: a multicenter study of 50 patients, part 2: epidemiology, clinical presentation, radiological and laboratory features, treatment responses, and long-term outcome. J Neuroinflammation. 2016;13(1):280.

2. Pittock SJ, Weinshenker BG, Wijdicks EF. Mechanical ventilation and tracheostomy in multiple sclerosis. J Neurol Neurosurg Psychiatry. 2004;75(9):1331-1333.

3. Wingerchuk DM, Hogancamp WF, O'Brien PC, Weinshenker BG. The clinical course of neuromyelitis optica (Devic's syndrome). Neurology. 1999;53(5):1107-1114.

4. Hyun JW, Kim G, Kim Y, Jeong IH, Kim SH, Kim HJ. Severe relapse after cessation of immunosuppressive therapy in a patient with neuromyelitis optica spectrum disorder. Neurologist. 2016;21(6):97-98.

5. Flanagan EP, Cabre P, Weinshenker BG, et al. Epidemiology of aquaporin-4 autoimmunity and neuromyelitis optica spectrum. Ann Neurol. 2016;79(5):775-783.

6. Mealy MA, Wingerchuk DM, Greenberg BM, Levy M. Epidemiology of neuromyelitis optica in the United States: a multicenter analysis. Arch Neurol. 2012;69(9):1176-1180.

7. Kitley J, Leite MI, Nakashima I, et al. Prognostic factors and disease course in aquaporin-4 antibody-positive patients with neuromyelitis optica spectrum disorder from the United Kingdom and Japan. Brain. 2012;135(pt 6):1834-1849.

8. Sepulveda M, Armangue T, Sola-Valls N, et al. Neuromyelitis optica spectrum disorders: comparison according to the phenotype and serostatus. Neurol Neuroimmunol Neuroinflamm. 2016;3(3):e225.

9. Mealy MA, Kessler RA, Rimler Z, et al. Mortality in neuromyelitis optica is strongly associated with African ancestry. Neurol Neuroimmunol Neuroinflamm. 2018;5(4):e468.

10. Waters PJ, McKeon A, Leite MI, et al. Serologic diagnosis of NMO: a multicenter comparison of aquaporin-4-IgG assays. Neurology. 2012;78(9):665-671.

11. López-Chiriboga AS, Majed M, Fryer J, et al. Association of MOG-IgG serostatus with relapse after acute disseminated encephalomyelitis and proposed diagnostic criteria for MOG-IgG-associated disorders. JAMA Neurol. 2018;75(11):1355-1363.

12. Jarius S, Paul F, Aktas O, et al. MOG encephalomyelitis: international recommendations on diagnosis and antibody testing. J Neuroinflamm. 2018;15(1):134.

13. Wingerchuk DM, Banwell B, Bennett JL, et al. International consensus diagnostic criteria for neuromyelitis optica spectrum disorders. Neurology. 2015;85(2):177-189.

14. Flanagan EP. Neuromyelitis optica spectrum disorder and other non-multiple sclerosis central nervous system inflammatory diseases. Continuum. 2019;25(3):815-844.

15. Bonnan M, Valentino R, Debeugny $S$, et al. Short delay to initiate plasma exchange is the strongest predictor of outcome in severe attacks of NMO spectrum disorders. J Neurol Neurosurg Psychiatry. 2018;89(4):346-351.

16. Kim SH, Kim W, Li XF, Jung IJ, Kim HJ. Does interferon beta treatment exacerbate neuromyelitis optica spectrum disorder? Mult Scler. 2012;18(10):1480-1483.

17. Jacob A, Hutchinson M, Elsone L, et al. Does natalizumab therapy worsen neuromyelitis optica? Neurology. 2012;79(10):1065-1066.

18. Fiscella K, Franks P, Gold MR, Clancy CM. Inequality in quality: addressing socioeconomic, racial, and ethnic disparities in health care. JAMA. 2000;283(19): 2579-2584.

19. Ogawa R, Nakashima I, Takahashi T, et al. MOG antibody-positive, benign, unilateral, cerebral cortical encephalitis with epilepsy. Neurol Neuroimmunol Neuroinflamm. 2017;4(2):e322.

20. Lopez-Chiriboga S, Sechi E, Buciuc M, et al. Long-term outcomes in patients with myelin oligodendrocyte glycoprotein immunoglobulin G-associated disorder. JAMA Neurol. 2020;77(12):1575-1577.

21. Jurynczyk M, Messina S, Woodhall MR, et al. Clinical presentation and prognosis in MOG-antibody disease: a UK study. Brain. 2017;140(12):3128-3138.

22. Deschamps R, Pique J, Ayrignac X, et al. The long-term outcome of MOGAD: an observational national cohort study of 61 patients. Eur J Neurol. 2021;28(5): 1659-1664.

23. Kleiter I, Gahlen A, Borisow N, et al. Neuromyelitis optica: evaluation of 871 attacks and 1,153 treatment courses. Ann Neurol. 2016;79(2):206-216. 


\section{Neurology}

\section{CNS Demyelinating Attacks Requiring Ventilatory Support With Myelin Oligodendrocyte Glycoprotein or Aquaporin-4 Antibodies}

Hannah H. Zhao-Fleming, Cristina Valencia Sanchez, Elia Sechi, et al. Neurology 2021;97;e1351-e1358 Published Online before print August 13, 2021

DOI 10.1212/WNL.0000000000012599

This information is current as of August 13, 2021

\section{Updated Information \& Services}

References

Citations

Subspecialty Collections

Permissions \& Licensing

Reprints including high resolution figures, can be found at: http://n.neurology.org/content/97/13/e1351.full

This article cites 23 articles, 8 of which you can access for free at: http://n.neurology.org/content/97/13/e1351.full\#ref-list-1

This article has been cited by 1 HighWire-hosted articles: http://n.neurology.org/content/97/13/e1351.full\#\#otherarticles

This article, along with others on similar topics, appears in the following collection(s):

Acute disseminated encephalomyelitis

http://n.neurology.org/cgi/collection/acute_disseminated_encephalomy elitis

Inclusion, Diversity, Equity, Anti-racism, and Social Justice (IDEAS)

http://n.neurology.org/cgi/collection/all_equity_diversity_and_inclusio $\mathrm{n}$

Transverse myelitis

http://n.neurology.org/cgi/collection/transverse_myelitis

Information about reproducing this article in parts (figures,tables) or in its entirety can be found online at:

http://www.neurology.org/about/about_the_journal\#permissions

Information about ordering reprints can be found online:

http://n.neurology.org/subscribers/advertise

Neurology ${ }^{\circledR}$ is the official journal of the American Academy of Neurology. Published continuously since 1951, it is now a weekly with 48 issues per year. Copyright Copyright ( 2021 The Author(s). Published by Wolters Kluwer Health, Inc. on behalf of the American Academy of Neurology.. All rights reserved. Print ISSN: 0028-3878. Online ISSN: 1526-632X.

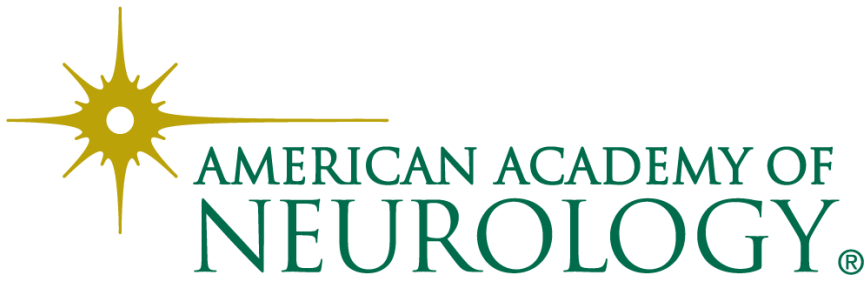

